\title{
MULTI-WIRE SUBMERGED ARC WELDING: A STUDY OF SECONDARY PROCESS PARAMETERS
}

\author{
W. Boudry ${ }^{1}$, E. Delboo ${ }^{1}$, K. Faes ${ }^{2}$, E. Van Pottelberg ${ }^{3}$, W. De Waele ${ }^{4}$ \\ ${ }^{1}$ Ghent University, Belgium \\ ${ }^{2}$ Belgian Welding Institute, Belgium \\ ${ }^{3}$ OCAS, Belgium \\ ${ }^{4}$ Ghent University, Laboratory Soete, Belgium
}

\begin{abstract}
The goal of this thesis is to investigate the effect of secondary process parameters on the geometry of the weld bead in multi-wire submerged arc welding. Bead-on-plate welding experiments will be conducted using 3, 4 and 5 wires. The parameters being varied will be the wire stick out, the angles of the torches and the spacing in between. Primary process parameters like voltage, current and welding speed will be kept constant. Penetration, bead width and height, percentage dilution, HAZ, weld penetration shape factor and weld reinforcement shape factor will be measured and evaluated. Fewer experiments will be needed because of the use of a design of experiments approach, namely a fractional factorial design. This will allow to determine the significance of each single parameter and their mutual interaction with respect to weld bead shape.
\end{abstract}

Keywords: Multi-wire; Submerged arc welding; Design of experiments; Secondary parameters; Fractional factorial

\section{INTRODUCTION}

Multi-wire submerged arc welding (SAW) is a high deposition rate process that is frequently used for piping and offshore applications. It is capable of joining thick steel plates or pipes in a fully automated process at high speed, which makes it economically very interesting to use for relatively large production series. Typically process parameters are set using rules of thumb and optimised through trial and error. Once good parameters are found, they are kept constant for the entire batch. In a previous master thesis the effect of primary process parameters (voltage, current, welding speed) on the geometrical quality of plate butt welds has been experimentally evaluated [3]. This study will focus on the effect of secondary process parameters on the geometrical weld quality. First, a short description of the multi-wire SAW process is given followed by a discussion of primary and secondary process parameters. Next, the experimental approach designed to evaluate the effects of secondary process parameters is elaborated.

\section{MULTI-WIRE SUBMERGED ARC WELDING}

\subsection{Process description}

Submerged arc welding is a form of arc welding in which the weld pool is shielded by a mineral weld flux. This flux protects the weld pool from atmospheric influences, provides alloying elements to the weld pool and has several other properties that influence the weld [4]. The arc is formed within the flux and causes the continuously fed wire electrode to melt off and dilute with the molten base material. Because the arc is submerged, the heat loss is minimum resulting in a thermal efficiency as high as $95 \%$ [5]. No eye protection is needed [4-8], but this also implies that no visual monitoring can be done during welding [8]. This causes the need for automation [2, 4]. To increase productivity, multiple wires can be fed into the same weld pool (see Figure 1). Every single wire can have different settings, which gives each of them a specific role. The first wire has specific settings to cause a deep penetration $[6,8,9]$, the other wires have a more filling function. This makes it possible to weld thick plates using only one run [10]. The automation causes a need for accurate parameter settings. 


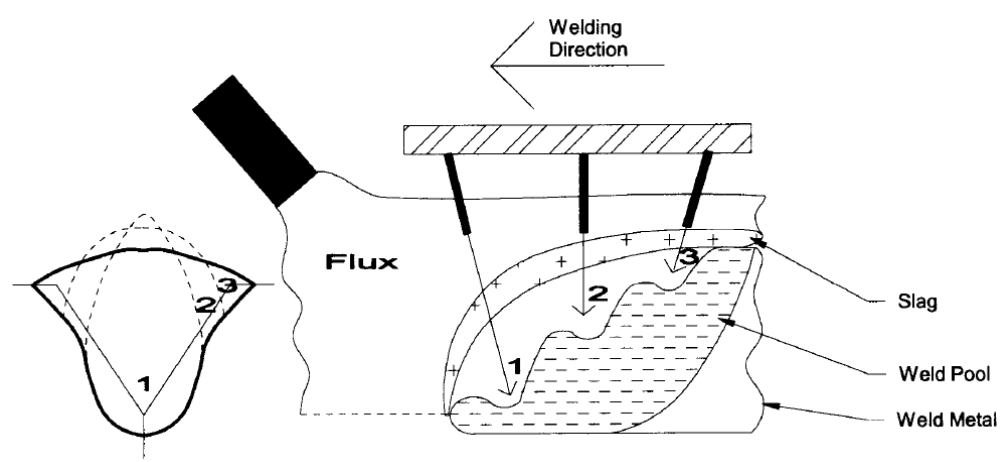

Figure 1. Schematic diagram illustrating filling of weld pool and formation of weld bead in a three-wire submerged arc welding procedure [11]

\subsection{Primary process parameters}

The primary process parameters are voltage, current and welding speed. These have been widely studied and discussed in literature. Since it is not the scope of this study, this section is limited to a brief summary of the main findings.

The main effect of voltage is the bead width. The larger the voltage, the wider the weld (see Figure 2). Some sources state that generally speaking the penetration reduces a little when voltage is increased [2, 8 , 11-14], but when used for butt welds or bead-on-plate welds, the penetration remains the same. Penetration will reduce for V-shape weld preparations [1].

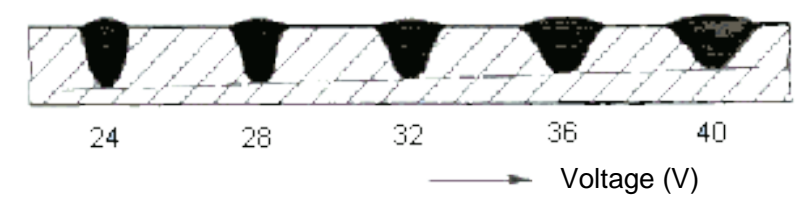

Figure 2. Effect of voltage on bead shape [2]

The current's main effect is the depth of penetration. The higher the current, the deeper the penetration (see Figure 3), causing a higher dilution percentage [1, 2, 8, 11-14].

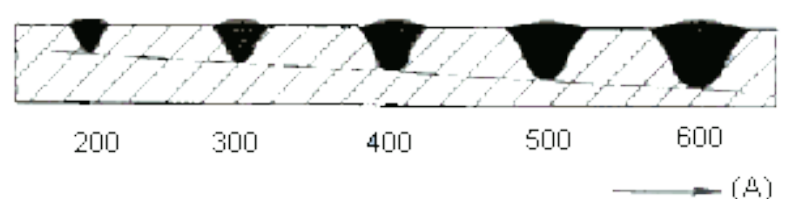

Figure 3. Effect of current on bead shape [2]

The welding speed can be seen as a scaling factor. Increasing the speed results in less time at a given position to produce a weld. This means that there is less heat input (Voltage $\times$ Current / Speed) creating a weld with less penetration and narrower bead [1, 2, 8, 11-14].

With increasing number of wires, the welding speed has to increase to limit the total heat input.

\subsection{Secondary process parameters}

The main goal of this master thesis is to investigate the influence of secondary process parameters on geometrical weld quality. There is a long list of secondary parameters; this study will focus on stick out, angles of the electrodes and spacing in between. Since information on these parameters is scarce in scientific literature, manufacturers of SAW machines have been interviewed.

Stick out is the vertical distance between the plate and the contact tube where the current is supplied to the electrode wire. When stick out is increased, more heat will be dissipated in the electrode due to increased resistance and thus resistive heating $[1,2,14]$. This last is proportional to $I^{2} R$, with $I$ the welding current and $R$ the resistance of the welding wire from the contact point to the arc. Increased stick out results in less penetration (see Figure 4). The resistive heating of the electrode with larger stick out increases the deposition rate $[1,8,14]$. This can be beneficially used for cladding. The increased temperature of the electrode makes it softer and increases the tendency to wander, introducing misalignment $[1,8]$. 


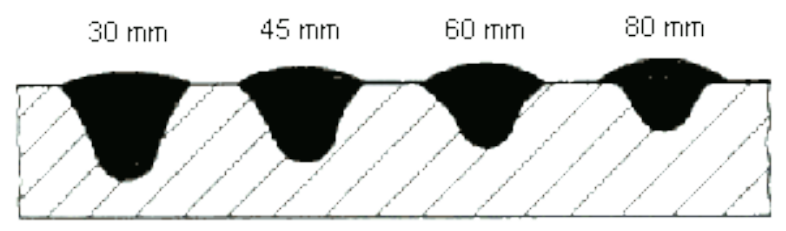

Figure 4. Effect of stick out on bead shape [2]

In a previous study using design of experiments [15], it was found that increasing stick out tends to increase hardness, decrease the charpy impact energy and decrease the yield stress (see Figure 5). The rate of increase of hardness with increase in stick out was found to be different for different levels of current.
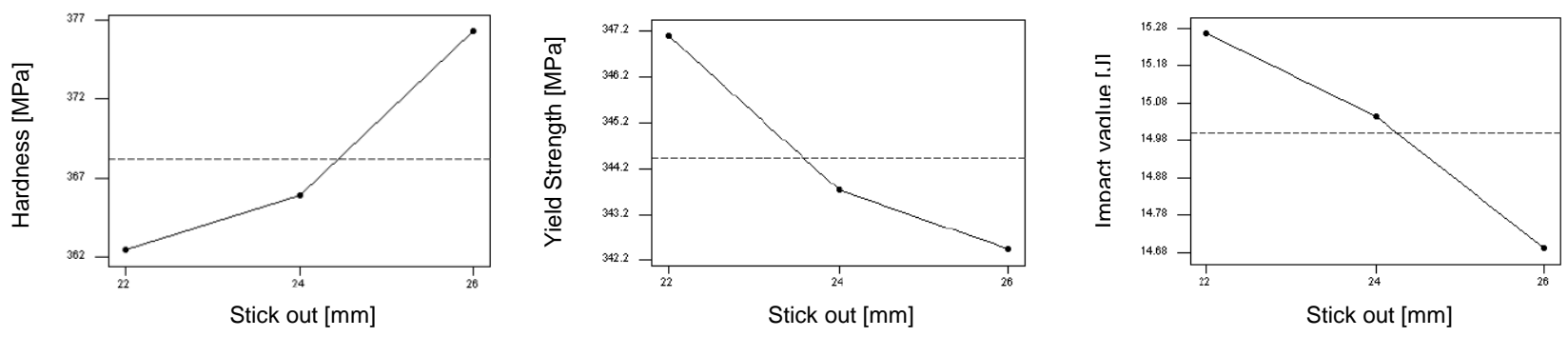

Figure 5. Effect of stick out on mechanical properties [15]

A practical rule of thumb is to set the stick out length equal to 8 times the wire diameter [13].

The angle of the electrode has a large influence on the bead shape. The electrode can point backward or forward relative to the welding direction. A backward pointing electrode (also called trailing electrode, because the tip follows the nozzle) results in higher penetration and narrower bead (see Figure 6) $[2,8,16]$. This can also cause undercut [1].

A forward pointing electrode (also called leading electrode, because the tip is in front of the nozzle) results in a shallower, wider bead (see Figure 6) because the arc burns on the melt pool and pushes the molten material to the sides $[2,8,16]$.

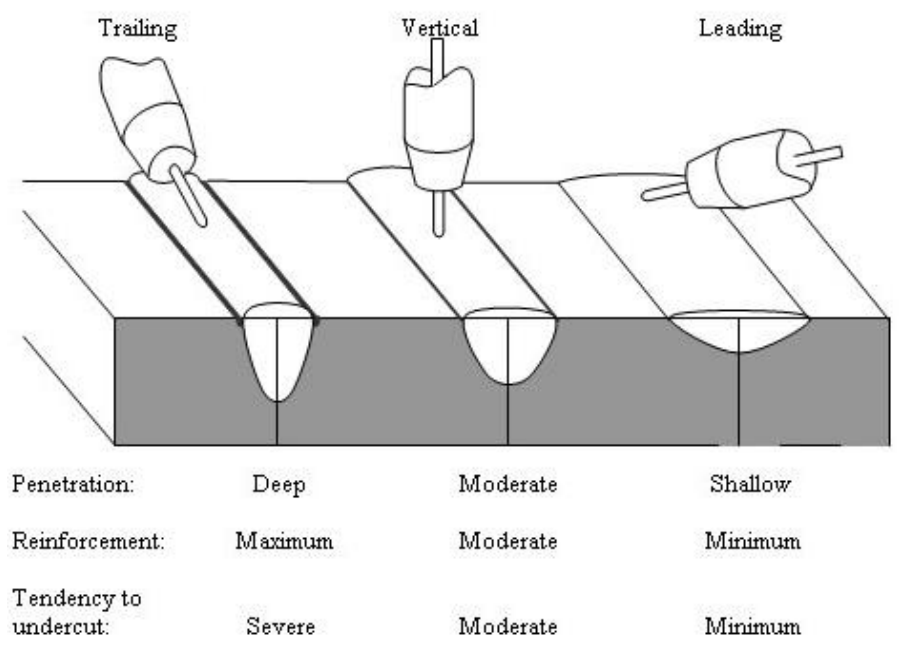

Figure 6. Effect of the electrode angle on weld shape [1]

In multi-wire applications, these effects are combined. The first wire is a trailing wire, causing almost $90 \%$ of the penetration [11]. The following wires gradually become more leading to fill up the weld (see Figure 1). This helps to remove the undercut and result in a flatter, smoother weld surface. It is also the only possible configuration because of the mechanical restraints of the machine in order to achieve spacing values of about $20 \mathrm{~mm}$. 
Not much is to be found on the effect of spacing in scientific literature. Manufacturers of SAW machines generally recommend values around $20 \mathrm{~mm}$, but no effects of changing these values are given. Miller is the only one giving a trend [13]; increasing the spacing reduces the penetration depth and arc stability but increases the bead width. It is also predicted that in 3-wire SAW, the spacing between the first and second electrode is more likely to change the bead shape than the spacing between the second and the third electrode [11].

\section{EXPERIMENTAL STUDY}

\subsection{Introduction to Design of Experiments}

To evaluate the effect of the secondary process parameters, a series of welding experiments will be performed. For the five-wire submerged arc welding process, the number of variables is fourteen; 5 stick out lengths, 5 angles and 4 spacing values.

The effect of each process variable (further called input parameter) on a weld quality aspect (further called output parameter) can be found by varying this single input parameter within a certain range and keeping all others constant. This will however only reveal information on the main effects of each individual input parameter, and not on the interaction effects of several input parameters. Hereto every possible combination of input parameters has to be tested. If such test series is performed and each input parameter is evaluated at two levels, this is called a full factorial design which requires $2^{n}$ experiments with $n$ the number of parameters. It can be understood that the number of tests easily exceeds the limitations on time and resources as every additional input parameter considered doubles the number of experiments.

However, one can reasonably assume that the effects of higher order interactions are small relative to the effects of individual factors and lower order interactions. This is the foundation of a fractional factorial design which allows to reduce the number of tests drastically. The number of experiments needed for problems with $n$ inputs can be reduced from $2^{n}$ to $2^{n-p}$. This means that only half of the tests are needed if $p=1$ and only a quarter when $p=2$. The result of this approach is confounding (or aliasing) of $p$ input parameters with $p$ parameter combinations [17]. In other words, it will not be possible to distinguish some individual parameter effects from some interaction effects. Assuming that the effect of individual factors will be much stronger than the effect of (higher order) interactions this should still give satisfactory estimations for the influence of the individual factors.

This technique has proven its efficiency in previous studies [18, 19] and industrial applications [17]. In recent years, Laboratory Soete has applied this technique several times with success in master theses and Ph.D.'s [20, 21].

\subsection{Experimental design}

As stated higher, this study is characterized by fourteen variables. To reduce the number of experiments, first the number of input parameters is reduced to six.

Stick out will be identical for all torches, thus resulting in 1 general stick out parameter. The five angles will be reduced to 3 input parameters. In the case of 3 wire SAW welding, there are only 3 angles. In case of 4 and 5 wires, the angles of the first and last torches are 2 input parameters. The other torch angles will be set equal and are grouped into a third angle parameter. For spacing, there will be 2 input parameters. In case of 4 and 5 wires, the spacing between first and second wire and between second and third wire are equal and represented with the first spacing parameter. The remaining spacing values (between third and fourth and fourth and fifth) are equal and represented by the second spacing parameter.

One parameter for stick out, three parameters for the angles and two parameters for spacing result in a total of six parameters for the fractional factorial design. Evaluating every input parameters at two levels and choosing a confounding level of $p=2$ this results in $2^{6-2}=16$ experiments to be performed (see Table 1 ). This makes it a design of resolution IV. 
Table 1. Coded design matrix in a 6-factor (2-level) 16-run fractional factorial design [17]

\begin{tabular}{|c|c|c|c|c|c|c|c|c|c|c|c|c|c|c|}
\hline run & $\mathrm{A}$ & $\mathrm{B}$ & $\mathrm{C}$ & $\mathrm{D}$ & $\mathrm{AB}$ & $\mathrm{AC}$ & $\mathrm{AD}$ & $\mathrm{BC}$ & $\mathrm{BD}$ & $\mathrm{CD}$ & $\mathrm{ABC}$ & $\mathrm{ACD}=\mathrm{E}$ & $\mathrm{BCD}=\mathrm{F}$ & $\mathrm{ABCD}$ \\
\hline 1 & -1 & -1 & -1 & -1 & 1 & 1 & 1 & 1 & 1 & 1 & -1 & -1 & -1 & 1 \\
\hline 2 & -1 & -1 & -1 & 1 & 1 & 1 & -1 & 1 & -1 & -1 & -1 & 1 & 1 & -1 \\
\hline 3 & -1 & -1 & 1 & -1 & 1 & -1 & 1 & -1 & 1 & -1 & 1 & 1 & 1 & -1 \\
\hline 4 & -1 & -1 & 1 & 1 & 1 & -1 & -1 & -1 & -1 & 1 & 1 & -1 & -1 & 1 \\
\hline 5 & -1 & 1 & -1 & -1 & -1 & 1 & 1 & -1 & -1 & 1 & 1 & -1 & 1 & -1 \\
\hline 6 & -1 & 1 & -1 & 1 & -1 & 1 & -1 & -1 & 1 & -1 & 1 & 1 & -1 & 1 \\
\hline 7 & -1 & 1 & 1 & -1 & -1 & -1 & 1 & 1 & -1 & -1 & -1 & 1 & -1 & 1 \\
\hline 8 & -1 & 1 & 1 & 1 & -1 & -1 & -1 & 1 & 1 & 1 & -1 & -1 & 1 & -1 \\
\hline 9 & 1 & -1 & -1 & -1 & -1 & -1 & -1 & 1 & 1 & 1 & 1 & 1 & -1 & -1 \\
\hline 10 & 1 & -1 & -1 & 1 & -1 & -1 & 1 & 1 & -1 & -1 & 1 & -1 & 1 & 1 \\
\hline 11 & 1 & -1 & 1 & -1 & -1 & 1 & -1 & -1 & 1 & -1 & -1 & -1 & 1 & 1 \\
\hline 12 & 1 & -1 & 1 & 1 & -1 & 1 & 1 & -1 & -1 & 1 & -1 & 1 & -1 & -1 \\
\hline 13 & 1 & 1 & -1 & -1 & 1 & -1 & -1 & -1 & -1 & 1 & -1 & 1 & 1 & 1 \\
\hline 14 & 1 & 1 & -1 & 1 & 1 & -1 & 1 & -1 & 1 & -1 & -1 & -1 & -1 & -1 \\
\hline 15 & 1 & 1 & 1 & -1 & 1 & 1 & -1 & 1 & -1 & -1 & 1 & -1 & -1 & -1 \\
\hline 16 & 1 & 1 & 1 & 1 & 1 & 1 & 1 & 1 & 1 & 1 & 1 & 1 & 1 & 1 \\
\hline
\end{tabular}

In the above table, the six input parameters are denoted as $A$ to $F$. The numbers 1 and -1 represent the maximum and minimum parameter values respectively. Two factors ( $E$ and $F$ ) are each aliased with a 3way interaction. The coded matrix for all terms (not in this paper) shows all aliases in the fractional factorial design. The individual factors are aliased with 3-way interactions, which justifies the choice of aliasing as the effects of 3-way interactions can be assumed insignificant compared to the individual factors. The 2way interactions are aliased with other 2-way interactions. To determine which 2-way interaction is most significant when several aliased 2-way interactions seem to be important, we have to rely on common sense to determine which factors are most likely to interact. For example it is unusual for a 2-way interaction to be significant if one the interacting factors is not significant by itself.

To improve the statistical value of the results, the experiments will be replicated. This results in a total of 32 runs per welding configuration. According to Appendix $\mathrm{M}$ of [17] this replication gives a detection rate of $99 \%$ for the mean value and $75 \%$ for the variance, if a confidence level of $95 \%$ is chosen.

\subsection{Experimental setup}

Tests will be performed using a welding robot from ESAB, consisting of a moving horizontal beam, mounted on a vertical beam which allows the horizontal beam to go up and down. The vertical beam is mounted on a carriage that can ride over rails. It can rotate relative to the carriage, giving the robot a large working area. For our tests, the carriage and the vertical beam will be locked. Only the horizontal arm moves: up and down on the vertical beam to adjust the height and lengthwise to perform the weld. The tests will be done using a 5-wire SAW welding head from ESAB with separate power sources for each wire. Bead welds will be realized by means of 3 wire, 4 wire and 5 wire SAW processes.

The chosen welding wire is a $4 \mathrm{~mm}$ OK Autrod 12.24 type for all torches. This is a copper coated, molybdenum alloyed wire for the submerged arc welding of non-alloyed and low-alloyed steels. In combination with OK Flux 10.74, bead-on-plate welds will be performed on $50 \mathrm{~mm}$ thick S355 construction steel plates. The flux has been chosen for its low basicity giving it a sufficient current carrying capacity for multiwire welding at high speed. The length of the welds is set at approximately 1 meter to obtain a steady state section of sufficient length in the weld. Multiple welds will be applied on one plate parallel to each other with a certain spacing distance to avoid interference of their heat affected zones.

Both primary and secondary process parameters have been set forward based on literature findings and suggestions by specialised companies. An overview is given in

Table 2. 
Table 2. Primary and secondary parameters

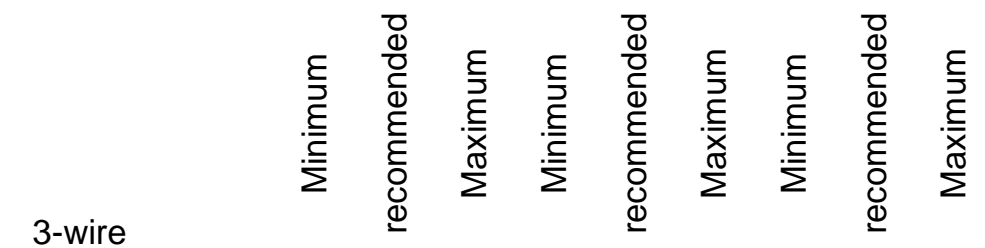

\begin{tabular}{|l|r|r|r|r|r|r|r|r|r|}
\hline wire & \multicolumn{2}{|c|}{1} & \multicolumn{2}{c|}{2} & \multicolumn{3}{c|}{3} \\
\hline voltage (V) & \multicolumn{2}{|c|}{30} & \multicolumn{3}{c|}{34} & \multicolumn{3}{c|}{38} \\
\hline current (A) & \multicolumn{2}{|c|}{1100} & \multicolumn{3}{c|}{900} & \multicolumn{3}{c|}{700} \\
\hline speed(m/min) & \multicolumn{2}{|c|}{1,2} & \multicolumn{3}{|c|}{1,2} & \multicolumn{3}{c|}{1,2} \\
\hline S.O. $(\mathrm{mm})$ & 30 & 35 & 40 & 30 & 35 & 40 & 30 & 35 & 40 \\
\hline angle $\left({ }^{\circ}\right)$ & -5 & 0 & 5 & 3 & 8 & 13 & 12 & 17 & 22 \\
\hline spacing $(\mathrm{mm})$ & 13 & 18 & 23 & 13 & 18 & 23 & & & \\
\hline
\end{tabular}

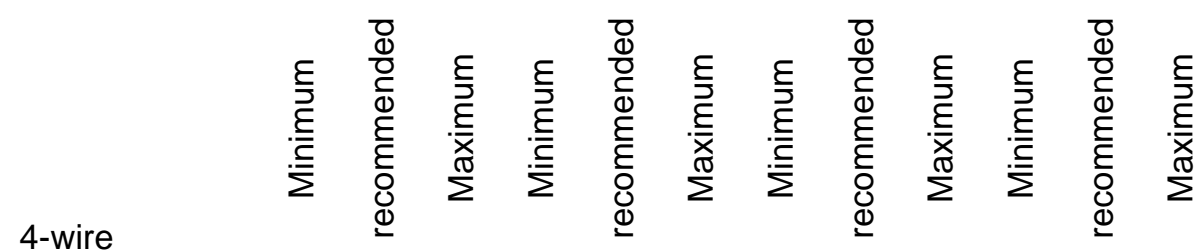

\begin{tabular}{|c|c|c|c|c|c|c|c|c|c|c|c|c|}
\hline wire & \multicolumn{3}{|c|}{1} & \multicolumn{3}{|c|}{2} & \multicolumn{3}{|c|}{3} & \multicolumn{3}{|c|}{4} \\
\hline voltage $(\mathrm{V})$ & \multicolumn{3}{|c|}{30} & \multicolumn{3}{|c|}{34} & \multicolumn{3}{|c|}{36} & \multicolumn{3}{|c|}{38} \\
\hline current $(A)$ & \multicolumn{3}{|c|}{1100} & \multicolumn{3}{|c|}{850} & \multicolumn{3}{|c|}{650} & \multicolumn{3}{|c|}{550} \\
\hline $\operatorname{speed}(\mathrm{m} / \mathrm{min})$ & \multicolumn{3}{|c|}{1,5} & \multicolumn{3}{|c|}{1,5} & \multicolumn{3}{|c|}{1,5} & \multicolumn{3}{|c|}{1,5} \\
\hline S.O. $(\mathrm{mm})$ & 30 & 35 & 40 & 30 & 35 & 40 & 30 & 35 & 40 & 30 & 35 & 40 \\
\hline angle $\left(^{\circ}\right)$ & -17 & -12 & -7 & -5 & 0 & 5 & 3 & 8 & 13 & 15 & 20 & 25 \\
\hline spacing $(\mathrm{mm})$ & 13 & 18 & 23 & 13 & 18 & 23 & 15 & 20 & 25 & & & \\
\hline
\end{tabular}

\begin{tabular}{|c|c|c|c|c|c|c|c|c|c|c|c|c|c|c|c|}
\hline wire & \multicolumn{3}{|c|}{1} & \multicolumn{3}{|c|}{2} & \multicolumn{3}{|c|}{3} & \multicolumn{3}{|c|}{4} & \multicolumn{3}{|c|}{5} \\
\hline voltage (V) & \multicolumn{3}{|c|}{30} & \multicolumn{3}{|c|}{33} & \multicolumn{3}{|c|}{35} & \multicolumn{3}{|c|}{37} & \multicolumn{3}{|c|}{40} \\
\hline current $(\mathrm{A})$ & \multicolumn{3}{|c|}{1100} & \multicolumn{3}{|c|}{900} & \multicolumn{3}{|c|}{750} & \multicolumn{3}{|c|}{600} & \multicolumn{3}{|c|}{500} \\
\hline $\operatorname{speed}(\mathrm{m} / \mathrm{min})$ & \multicolumn{3}{|c|}{2} & \multicolumn{3}{|c|}{2} & & \multicolumn{3}{|c|}{2} & \multicolumn{3}{|c|}{2} \\
\hline S.O. $(\mathrm{mm})$ & 30 & 35 & 40 & 30 & 35 & 40 & 30 & 35 & 40 & 30 & 35 & 40 & 30 & 35 & 40 \\
\hline angle $\left(^{\circ}\right)$ & -15 & -10 & -5 & -5 & 0 & 5 & 3 & 8 & 13 & 13 & 18 & 23 & 20 & 25 & 30 \\
\hline spacing (mm) & 13 & 18 & 23 & 13 & 18 & 23 & 15 & 20 & 25 & 15 & 20 & 25 & & & \\
\hline
\end{tabular}


Before the actual test series, preliminary trial-and-error tests will be carried out to validate some of the parameter settings. Especially the ranges for the secondary parameters, main focus of this investigation, need to be screened.

After welding, samples will be cut from each weld to investigate the geometrical quality of the weld beads. To this end penetration, bead width, reinforcement height and HAZ will be measured. From these 4 geometrical measurements, some deviated factors can be calculated such as percentage dilution, weld penetration shape factor and weld reinforcement shape factor. As a measure of the mechanical quality, some hardness measurements will be performed. Each of these properties can then be used as output for the fractional factorial. This should lead us to an evaluation of the effects of the secondary parameters on each output property.

\section{CONCLUSIONS}

The effect of secondary parameters on submerged arc welding bead geometry is a topic on which little research has been published yet. There are many secondary parameters that can be investigated. Stick out, angles and spacing are selected. To keep the number of tests within reasonable limits, concerning time and resources, a fractional factorial design of experiments has been elaborated. This should allow to evaluate the importance of the selected parameters and their interactions on bead geometry.

\section{NOMENCLATURE}

SAW Submerged arc welding

HAZ Heat affected zone

\section{ACKNOWLEDGEMENTS}

The authors would like to acknowledge the input on secondary process parameters received from several contractors and welding machine suppliers..

\section{REFERENCES}

1. Arcraft Plasma Equipments. Submerged arc welding. Available from: http://www.arcraftplasma.com/.

2. Vanotools. Vergelijking van verschillende toepasbare lasprocessen. 2006; Available from: www.vanotools.nl.

3. Dhollander, R. and S. Vancauwenberghe, Meerdraads onderpoederdek lassen van stalen structuren, in Faculteit Ingenieurswetenschappen. 2012, Universiteit Gent: Gent. p. 150.

4. $\quad$ Depessemier, J.-P., Cursus OP-lassen BIL. 2008.

5. Kumanan, S., J.E.R. Dhas, and K. Gowthaman, Determination of submerged are welding process parameters using Taguchi method and regression analysis. Indian Journal of Engineering and Materials Sciences, 2007. 14(3): p. 177-183.

6. Alam, S. and M.I. Khan, Prediction of the Effect of Submerged Arc Welding Process Parameters on Weld Bead Width for MS 1018 Steel. International Journal of Engineering and Innovative Technology, 2012. 1(5): p. 8.

7. Saluja, R. and K.M. Moeed, Modeling and Parametric Optimization using Factorial Design Approach of Submerged Arc Bead Geometry for Butt Joint. International Journal of Engineering Research and Applications, 2012. 2(3): p. 4.

8. ESAB. Submerged Arc Welding Handbook. 1999 [cited 2012 December]; Available from: http://www.esabna.com.

9. SRIVASTAVA, B.K., S.P. TEWARI, and J. PRAKASH, A REVIEW ON EFFECT OF ARC WELDING PARAMETERS ON MECHANICAL BEHAVIOUR OF FERROUS METALS/ALLOYS. International Journal of Engineering Science and Technology, 2010. 2(5): p. 8.

10. Murugan, N. and V. Gunaraj, Prediction and control of weld bead geometry and shape relationships in submerged arc welding of pipes. Journal of Materials Processing Technology, 2005. 168(3): p. 478-487. 
11. Ridings, G.E., R.C. Thomson, and G. Thewlis, Prediction of multiwire submerged arc weld bead shape using neural network modelling. Science and Technology of Welding and Joining, 2002. 7(5): p. 265-279.

12. Cvetkovski, S., et al., OPTIMIZATION OF WELDING PARAMETERS FOR GAS TRANSPORTATION STEEL PIPES. Metalurgija, 2010. 49(4): p. 331-334.

13. Miller Electric MFG. Submerged arc welding. 1982 [cited 2012 December]; Available from: http://www.millerwelds.com/.

14. SINGH, R.P., Parametric Effect on Mechanical Properties in Submerged arc welding process - A review. International Journal of Engineering Science and Technology, 2012. 4(2): p. 11.

15. S. Datta , M.S., A. Bandyopadhyay, G. Nandi, P.K. Pal and S.C. Roy. EFFECT OF ELECTRODE STICK OUT ON QUALITY AND PERFORMANCE OF SUBMERGED ARC WELDMENTEXPERIMENTAL AND STATISTICAL ANALYSES. in International Conference on Mechanical Engineering 2005. 2005. Dhaka, Bangladesh.

16. ESAB. SA_handbook. Available from: http://www.esabna.com.

17. Schmidt, S.R. and R.G. Launsby, Understanding Industrial Designed Experiments. 4 ed. 2005.

18. RAMASAMY, S., J. GOULD, and D. WORKMAN, Design-of-Experiments Study to Examine the Effect of Polarity on Stud Welding. Welding Journal, 2002: p. 8.

19. Kishore, K., et al., ANALYSIS OF DEFECTS IN GAS SHIELDED ARC WELDING OF AISI1040 STEEL USING TAGUCHI METHOD. ARPN Journal of Engineering and Applies Sciences, 2010. 5(1): p. 5.

20. Verstraete, M. and A. Zegers, Onderzoek naar de lasbaarheid van pijpleidingstaal m.b.v. het FRIEX proces, in Faculteit Ingenieurswetenschappen. 2009, Universiteit Gent: Gent. p. 208.

21. Wonterghem, M.V. and P. Vanhulsel, Magnetic pulse crimping of mechanical joints, in Faculteit Ingenieurswetenschappen. 2011, Universiteit Gent: Gent. p. 199. 